\title{
A comparative study: rural versus urban children as regard exposure to organophosphorus pesticides using cholinesterase enzyme activity
}

\author{
Yasmen A. Mohamed ${ }^{1 *}$, Mohamed Hussien Meabed ${ }^{1}$, Khadiga Mohamed Abougaba ${ }^{2}$, Fatma Ali Sayed ${ }^{1}$, \\ Nermeen N. Welson ${ }^{3}$ and Raghda Ebaid Ibrahim²
}

\begin{abstract}
Background: The uncontrolled long-term exposure to organophosphorus (OP) pesticides is hazardous to health especially in children. The present study aimed to determine the acetyl cholinesterase enzyme serum level in exposure and non-exposure children groups, to explore other clinical and laboratory outcomes of organophosphorus pesticides exposure on children living in rural versus urban areas, and to establish the hemotoxic alterations as a result of the exposure. A ninety clinically free children - forty-five from rural areas and forty-five children from urban areas - were assessed, and the clinical and laboratory effects of their exposure to organophosphorus pesticides were evaluated via measuring acetyl cholinesterase (AChE) enzyme activity.
\end{abstract}

Results: Significant differences between the two areas of residence were found in weight \%, visits to the field, eating vegetables without washing, presence of insecticides at home, and previous organophosphorus pesticides toxicity of the patients and their families. Eye, respiratory, cardiac, nervous, muscle, gastrointestinal, and urinary symptoms were more common in the rural residence group which shows more exposure to pesticides. The mean level of the AChE enzyme was less in the rural residence group than the other one, and it showed significant correlations with the anemia indicating parameters. A weak positive correlation was found with platelets count.

Conclusions: Chronic organophosphorus toxicity that is more prevalent in rural areas may result in many transient neglected symptoms, unrevealed acetyl cholinesterase (AChE) enzyme deficiency, anemia, and thrombocytopenia. Acetyl cholinesterase enzyme serum level can be used as a screening test for organophosphorus pesticides exposure.

Keywords: Chronic toxicity, Organophosphorus pesticides, Children, Cholinesterase enzyme, Hematotoxicity

\section{Key messages}

- Chronic organophosphorus toxicity results in many transient neglected symptoms.

- Chronic organophosphorus exposure results in unrevealed AchE deficiency.

\footnotetext{
*Correspondence: y.awadalh@yahoo.com

${ }^{1}$ Department of Pediatrics, Faculty of Medicine, Beni-Suef University, Beni Suef, Egypt

Full list of author information is available at the end of the article
}

- Chronic organophosphorus exposure is associated with unrevealed anemia and thrombocytopenia.

\section{Background}

Organophosphorus pesticides are the most commonly used class of insecticides; however, their improper use can harm people and other animals. Organophosphorus pesticides can cause chronic toxicity either through prolonged exposure for too long periods or through 
exposure to high sub-acute toxic doses [1]. The intensity of the symptoms varies according to the amount ingested, route of exposure, and the rate of metabolic detoxification of the chemicals. The most common ways of exposure are direct dermal contact and inhalation of the insecticide. The consumption of contaminated water or food is a less prevalent way of exposure [2].

The main mechanism of action of organophosphates is the suppression of carboxyl ester hydrolases, essentially acetylcholinesterase (AChE) which breaks down the neurotransmitter acetylcholine (ACh) into choline and acetic acid and it is present mainly in the central and peripheral nervous system, neuromuscular junctions, and red blood cells (RBCs) [3]. Organophosphates deactivate AChE via phosphorylating the serine hydroxyl group present at the active site of acetylcholinesterase. Over some time, phosphorylation is followed by the loss of organophosphate leaving the group and the bond with acetylcholinesterase becomes irreversible, a process that is known as aging [4]. Acetylcholinesterase enzyme activity is considered a specific marker for exposure to organophosphorus pesticides [5].

With acetylcholinesterase deactivation, acetylcholine increases in the nervous system causing overstimulation of muscarinic and nicotinic receptors. Clinical manifestations occur due to stimulation of the autonomic and central nervous systems and at nicotinic receptors on skeletal muscle [6]. The collective mnemonic that summarizes the muscarinic actions of organophosphate poisonings is defecation/diaphoresis, urination, miosis, bronchospasm/bronchorrhea, emesis, lacrimation, and salivation [7]. Other symptoms may involve anxiety, confusion, drowsiness, emotional lability, seizures, hallucinations, headaches, insomnia, memory loss, circulatory, or respiratory depression. The main cause of death is respiratory failure resulting from bronchoconstriction, bronchorrhea, central respiratory depression, or weakness/ paralysis of the respiratory muscles. Long-term complications can happen even after the resolution of acute toxicity. Pesticides have been shown to have hematotoxicity, neurotoxic, and genotoxic properties. They can induce aplastic anemia, agranulocytosis, neutropenia, and thrombocytopenia. Both acute and chronic pesticide toxicity can cause hematological, congenital abnormalities, and thalassemia. The interaction of organophosphate pesticides $(\mathrm{OP})$ with iron decreases the binding efficiency of Hemoglobin with iron leading to an anemic status [8].

No previous studies have documented the value of the normal serum level of acetylcholinesterase. It was reported to have a variable baseline and its role as a screening test was controversial if the post-exposure level was not compared to the pre-exposure level $[9,10]$. In the cases of chronic exposure, we cannot get a pre-exposure test. Therefore, the present study investigated the normal acetylcholinesterase serum level in agricultural children with known exposure to organophosphorus pesticides, compared it to the acetylcholinesterase level in the nonagricultural children, and correlated it with the other hematological parameters. This study aimed to monitor the various clinical and laboratory outcomes of the prolonged exposure to organophosphorus pesticide on children living in rural (agricultural) versus urban (nonagricultural) areas and to establish the hemotoxic alterations as a result of the exposure.

\section{Methods}

\subsection{Study design}

This is a preliminary cross-sectional descriptive study that included 90 clinically free children; 45 of them were from different agricultural areas who continuously visit fields with their parents and live beside these fields so they have been continuously exposed to organophosphorus pesticides and 45 children from urban areas. All pediatric age groups and both sexes were included. Cases with severe recent infections, immunological diseases, allergies, chronic diseases, traumatic, and congenital diseases were excluded.

\subsection{Clinical assessment}

Data were collected from participants including the age, sex, father work, mother work, visits to the fields, history of common unhealthy habits possibly increasing the exposure (e.g., eating vegetables without washing, use of insecticides at home), symptoms of previous exposure to organophosphorus including blurry or impaired vision, watery eye, narrowed pupils, stinging eyes, muscle twitching, muscle tremors, muscle fatigue or weakness, headache, dizziness, disorientation, confusion, convulsions, wheezing or coughing, sneezing, the difficulty of breathing, uncontrolled urination or bowel movements, severe diarrhea, severe vomiting, nausea, excessive secretions such as saliva, sweat, tears, and mucus, and irregular or slow heartbeats. Investigations were performed to assess the unrevealed toxicity.

\subsection{Laboratory investigations \\ 2.3.1 Complete blood count (using cell dyne Rudy, Abbott, USA)}

Venous blood samples $(5 \mathrm{~cm})$ were withdrawn from each child by a clean venipuncture without venous stasis, and precautions were taken to prevent frothing. Part of the blood was delivered in an EDTA tube $(2 \mathrm{~cm})$ to perform $\mathrm{CBC}$ (complete blood count). 


\subsubsection{Cholinesterase level (by ELISA)}

The rest of the blood sample $(3 \mathrm{~cm})$ was obtained and centrifuged for $15 \mathrm{~min}$ at $100 \times g$ at $2-8 \mathrm{c}$. The supernatant was aspirated and $100 \mu \mathrm{l}$ were applied to each well of the ELISA plate that was coated by cholinesterase antibody. Then, we added a biotinylated detection antibody specific for cholinesterase and Avidin-Horseradish Peroxidase (HRP) conjugate successively to each microplate well before incubation. Unbound components were washed away. The substrate solution was added to each well to terminate the enzyme-substrate reaction and the color changed into yellow color. The optical density (OD) was measured by an ELISA reader which was directly proportional to the concentration of the cholinesterase enzyme.

\subsection{Statistical analysis}

The SPSS software (Statistical Package for the Social Sciences, version 22.0, SPSS Inc, Chicago, IL, USA) was used for analysis. Comparison between qualitative data was carried out using the chi-square test and values were expressed as numbers and percentages. Parametric quantitative independent groups were examined using the $t$ test or the Mann-Whitney test and values were expressed as mean \pm standard deviation. One way ANOVA test was used to compare continuous variables between the three age groups. Predictors for poor outcomes were studied using the general linear multivariate analysis test. $p$ value was set at less than 0.05 for significant results.

\section{Results}

The mean age of the studied children was $(7.711 \pm 2.67)$ in rural and $(7.756 \pm 2.80)$ in urban areas, $43 \%$ were males and $47 \%$ were females. There was no significant difference between rural and urban as regard weight, height, and body mass index ( $p$ value $0.7,0.4,0.5$ ), respectively. Significance in the difference between the two areas of residence was found in Weight \% only (Table 1).

The significant variance between the two areas of residence was found in visits to the field, eating vegetables without washing, presence of insecticides at home, Previous OP toxicity of the patients, and family history of organophosphorus poisoning (Table 2).

Regarding the clinical symptoms, most of the recorded symptoms were more prevalent in the rural residence group and this variance between the two studied groups was statistically significant (Table 3 ).

Laboratory investigations showed that the rural residence group had Cholinesterase deficiency, anemia, and thrombocytopenia that were more obvious in comparison to the other group and the difference showed a
Table 1 Comparison between the urban and rural children as regarding demographic data

\begin{tabular}{|c|c|c|c|}
\hline & Urban (mean \pm SD) & Rural (mean \pm SD) & $p$ \\
\hline Age (years) & $7.7556 \pm 2.80548$ & $7.7111 \pm 2.67669$ & 0.939 \\
\hline \multicolumn{4}{|l|}{ Sex } \\
\hline Males & $22(48.9 \%)$ & $21(46.7 \%)$ & \multirow[t]{2}{*}{0.94} \\
\hline Females & $23(51.1 \%)$ & $24(53.3 \%)$ & \\
\hline Weight (kg) & $30.6533 \pm 9.41852$ & $30.1467 \pm 8.46859$ & 0.789 \\
\hline Weight \% & $61.5556 \pm 19.21240$ & $46.0000 \pm 15.54319$ & $<0.001$ \\
\hline Height (cm) & $125.2244 \pm 18.33834$ & $125.6044 \pm 17.71942$ & 0.446 \\
\hline Height \% & $45.2222 \pm 12.74557$ & $40.1111 \pm 13.07708$ & 0.068 \\
\hline $\mathrm{BMI} \mathrm{kg} \backslash \mathrm{m}$ & $19.1289 \pm 1.83559$ & $18.8244 \pm 1.93745$ & 0.507 \\
\hline \multicolumn{4}{|l|}{ Father education } \\
\hline None & $6(13.3 \%)$ & $6(13.3 \%)$ & \multirow[t]{4}{*}{0.79} \\
\hline Primary & $9(20.0 \%)$ & $7(15.6 \%)$ & \\
\hline Secondary & $20(44.4 \%)$ & $18(40.0 \%)$ & \\
\hline University & $10(22.2 \%)$ & $14(31.1 \%)$ & \\
\hline \multicolumn{4}{|l|}{ Mother education } \\
\hline None & $6(13.3 \%)$ & $6(13.3 \%)$ & \multirow[t]{4}{*}{0.32} \\
\hline Primary school & $10(22.2 \%)$ & $8(17.8 \%)$ & \\
\hline $\begin{array}{l}\text { Secondary } \\
\text { school }\end{array}$ & $26(57.8 \%)$ & $22(48.9 \%)$ & \\
\hline University & $3(6.7 \%)$ & $9(20.0 \%)$ & \\
\hline \multicolumn{4}{|l|}{ Father work } \\
\hline Employee & $31(68.9 \%)$ & $27(60.0 \%)$ & \multirow[t]{2}{*}{0.37} \\
\hline Worker & $14(31.1 \%)$ & $18(40.0 \%)$ & \\
\hline \multicolumn{4}{|l|}{ Mother work } \\
\hline Employee & $21(46.7 \%$ & $19(42.2 \%)$ & \multirow[t]{2}{*}{0.76} \\
\hline House wife & $24(53.3 \%)$ & $26(57.8 \%)$ & \\
\hline
\end{tabular}

Table 2 Comparison between urban and rural children as regarding history data

\begin{tabular}{lccc}
\hline & \multicolumn{2}{c}{ Group } & \multicolumn{1}{c}{$p$} \\
\cline { 2 - 3 } & Urban & Rural & \\
\hline Visits to the field & & & \\
$\quad$ No & $45(100.0 \%)$ & $16(35.6 \%)$ & $<0.001$ \\
$\quad$ Yes & $0(0.0 \%)$ & $29(64.4 \%)$ & \\
Eating vegetables without washing & & & \\
$\quad$ No & $41(91.1 \%)$ & $19(42.2 \%)$ & $<0.001$ \\
Yes & $4(8.9 \%)$ & $26(57.8 \%)$ & \\
Insecticides at home & & & \\
$\quad$ No & $38(84.4 \%)$ & $25(55.6 \%)$ & 0.003 \\
$\quad$ Yes & $7(15.6 \%)$ & $20(44.4 \%)$ & \\
Previous OP toxicity of the patients & & & \\
$\quad$ No & $45(100.0 \%)$ & $38(84.4 \%)$ & 0.006 \\
$\quad$ Yes & $0(0.0 \%)$ & $7(15.6 \%)$ & \\
FH of OPP & & & \\
$\quad$ No & $45(100.0 \%)$ & $31(68.9 \%)$ & $<0.001$ \\
Yes & $0(0.0 \%)$ & $14(31.1 \%)$ & \\
\hline
\end{tabular}


Table 3 Comparison between the study groups as regard frequency of clinical symptoms

\begin{tabular}{|c|c|c|c|}
\hline & \multicolumn{2}{|l|}{ Group } & \multirow[t]{2}{*}{$p$} \\
\hline & Urban & Rural & \\
\hline \multicolumn{4}{|l|}{ Eye symptoms } \\
\hline \multicolumn{4}{|c|}{ Eye symptoms } \\
\hline No & $43(95.6 \%)$ & $18(40.0 \%)$ & \multirow[t]{2}{*}{$<0.001$} \\
\hline Yes & $2(4.4 \%)$ & $27(60.0 \%)$ & \\
\hline \multicolumn{4}{|c|}{ Blurry or impaired vision } \\
\hline No & $42(93.3 \%)$ & $22(48.9 \%)$ & \multirow[t]{2}{*}{$<0.001$} \\
\hline Yes & $3(6.7 \%)$ & $23(51.1 \%)$ & \\
\hline \multicolumn{4}{|l|}{ Watery eye } \\
\hline No & $45(100.0 \%)$ & $24(53.3 \%)$ & \multirow[t]{2}{*}{$<0.001$} \\
\hline Yes & $0(0.0 \%)$ & $21(46.7 \%)$ & \\
\hline \multicolumn{4}{|c|}{ Narrowed pupils } \\
\hline No & $45(100.0 \%)$ & 31 (68.9\%) & \multirow[t]{2}{*}{$<0.001$} \\
\hline Yes & $0(0.0 \%)$ & $14(31.1 \%)$ & \\
\hline \multicolumn{4}{|l|}{ Stinging eye } \\
\hline No & $45(100.0 \%)$ & $26(57.8 \%)$ & \multirow[t]{2}{*}{$<0.001$} \\
\hline Yes & $0(0.0 \%)$ & $19(42.2 \%)$ & \\
\hline \multicolumn{4}{|c|}{ Respiratory symptoms } \\
\hline \multicolumn{4}{|c|}{ Respiratory symptoms } \\
\hline No & $37(82.2 \%)$ & $27(60.0 \%)$ & \multirow[t]{2}{*}{0.02} \\
\hline Yes & $8(17.8 \%)$ & $18(40.0 \%)$ & \\
\hline \multicolumn{4}{|l|}{ Runny nose } \\
\hline No & 37 (82.2\%) & $29(64.4 \%)$ & \multirow[t]{2}{*}{0.057} \\
\hline Yes & $8(17.8 \%)$ & $16(35.6 \%)$ & \\
\hline \multicolumn{4}{|l|}{ Sneezing } \\
\hline No & $42(93.3 \%)$ & $30(66.7 \%)$ & \multirow[t]{2}{*}{0.002} \\
\hline Yes & $3(6.7 \%)$ & $15(33.3 \%)$ & \\
\hline \multicolumn{4}{|l|}{ Cough } \\
\hline No & $39(86.7 \%)$ & $31(68.9 \%)$ & \multirow[t]{2}{*}{0.043} \\
\hline Yes & $6(13.3 \%)$ & $14(31.1 \%)$ & \\
\hline \multicolumn{4}{|c|}{ Difficult breathing } \\
\hline No & $45(100.0 \%)$ & $32(71.1 \%)$ & $<0.001$ \\
\hline Yes & $0(0.0 \%)$ & 13 (28.9\%) & \\
\hline Wheezing & & & \\
\hline No & 44 (97.8\%) & 32 (71.1\%) & $<0.001$ \\
\hline Yes & 1 (2.2\%) & 13 (28.9\%) & \\
\hline Cardiac symp & & & \\
\hline Irregular or sl & & & \\
\hline No & 45 (100\%) & $36(80.0 \%)$ & 0.002 \\
\hline Yes & 0 (0.0\%) & 9 (20.0\%) & \\
\hline CNS symptom & & & \\
\hline CNS symptor & & & \\
\hline No & 41 (91.1\%) & $24(53.3 \%)$ & $<0.001$ \\
\hline Yes & 4 (8.9\%) & $21(46.7 \%)$ & \\
\hline Confusion & & & \\
\hline No & $45(100.0 \%)$ & $30(66.7 \%)$ & $<0.001$ \\
\hline Yes & $0(0.0 \%)$ & $15(33.3 \%)$ & \\
\hline Convulsions & & & \\
\hline
\end{tabular}

Table 3 (continued)

\begin{tabular}{|c|c|c|c|}
\hline & Group & & $p$ \\
\hline & Urban & Rural & \\
\hline No & 45 (100.0\%) & 45 (100.0\%) & \\
\hline Yes & $0(0.0 \%) 0$ & $0(0.0 \%)$ & \\
\hline Coma & & & \\
\hline No & 45 (100.0\%) & 45 (100.0\%) & \\
\hline Yes & $0(0.0 \%) 0$ & 0 (0.0\%) & \\
\hline Headac & & & \\
\hline No & 41 (91.1\%) & 29 (64.4\%) & 0.002 \\
\hline Yes & $4(8.9 \%)$ & $16(35.6 \%)$ & \\
\hline Disorier & & & \\
\hline No & 45 (100.0\%) & $34(75.6 \%)$ & $<0.001$ \\
\hline Yes & $0(0.0 \%)$ & $11(24.4 \%)$ & \\
\hline Muscle. & & & \\
\hline Muscle & & & \\
\hline No & 42 (93.3\%) & $19(42.2 \%)$ & $<0.001$ \\
\hline Yes & $3(6.7 \%)$ & $26(57.8 \%)$ & \\
\hline Muscle & & & \\
\hline No & 45 (100.0\%) & 37 (82.2\%) & 0.003 \\
\hline Yes & $0(0.0 \%)$ & $8(17.8 \%)$ & \\
\hline Muscle & & & \\
\hline No & 42 (93.3\%) & $28(62.2 \%)$ & $<0.001$ \\
\hline Yes & $3(6.7 \%)$ & 17 (37.8\%) & \\
\hline Muscle & & & \\
\hline No & 45 (100.0\%) & 33 (73.3\%) & $<0.001$ \\
\hline Yes & $0(0.0 \%)$ & $12(26.7 \%)$ & \\
\hline GIT sym & & & \\
\hline GIT sym & & & \\
\hline No & 36 (80.0\%) & 18 (40.0\%) & $<0.001$ \\
\hline Yes & 9 (20.0\%) & $27(60.0 \%)$ & \\
\hline Salivatic & & & \\
\hline No & 45 (100.0\%) & 38 (92.7\%) & 0.065 \\
\hline Yes & $0(0.0 \%)$ & $3(7.3 \%)$ & \\
\hline Nausea & & & \\
\hline No & 39 (86.7\%) & $30(69.8 \%)$ & 0.054 \\
\hline Yes & $6(13.3 \%)$ & $13(30.2 \%)$ & \\
\hline Vomitir & & & \\
\hline No & 45 (100.0\%) & $28(62.2 \%)$ & $<0.001$ \\
\hline Yes & $0(0.0 \%)$ & $17(37.8 \%)$ & \\
\hline Diarrhe & & & \\
\hline No & 42 (93.3\%) & 29 (64.4\%) & 0.001 \\
\hline Yes & $3(6.7 \%)$ & $16(35.6 \%)$ & \\
\hline Uncont & & & \\
\hline No & 43 (95.6\%) & $28(65.1 \%)$ & $<0.001$ \\
\hline Yes & $2(4.4 \%)$ & 15 (34.9\%) & \\
\hline Urinary & & & \\
\hline Uncont & & & \\
\hline No & 45 (100.0\%) & 41 (91.1\% & 0.041 \\
\hline Yes & $0(0.0 \%)$ & $4(8.9 \%)$ & \\
\hline
\end{tabular}


Table 4 Comparison between cases and controls as regarding laboratory data

\begin{tabular}{|c|c|c|c|}
\hline & Urban (mean \pm SD) & Rural (mean $\pm S D$ ) & $p$ \\
\hline WBCs $\left(\times 10^{6} / \mathrm{mm}^{3}\right)$ & $7.0711 \pm 1.79806$ & $7.9911 \pm 1.69984$ & 0.014 \\
\hline $\operatorname{RBCs}\left(\times 10^{6} / \mathrm{mm}^{3}\right)$ & $4.4156 \pm .41885$ & $3.5933 \pm .95902$ & $<0.001$ \\
\hline HCT (vol \%) & $45.0311 \pm 3.04824$ & $35.0600 \pm 9.08624$ & $<0.001$ \\
\hline $\mathrm{Hb}(\mathrm{g} / \mathrm{dl})$ & $13.7133 \pm 1.14923$ & $11.2400 \pm 2.19280$ & $<0.001$ \\
\hline$M C V(\mu 3)$ & $84.6711 \pm 7.99254$ & $77.5289 \pm 11.26192$ & 0.001 \\
\hline $\mathrm{MCH}(\mathrm{pg})$ & $29.7044 \pm 2.49226$ & $25.5644 \pm 4.92277$ & $<0.001$ \\
\hline $\mathrm{MCHC}(\%)$ & $33.5889 \pm 2.09243$ & $30.4844 \pm 3.60404$ & $<0.001$ \\
\hline Platelets $\left(\times 10^{6} / \mathrm{mm}^{3}\right)$ & $298.4444 \pm 88.49513$ & $245.1778 \pm 120.54465$ & 0.019 \\
\hline Cholinesterase level(IU) & $77.4222 \pm 15.66044$ & $38.0222 \pm 30.20497$ & $<0.001$ \\
\hline \multicolumn{4}{|l|}{ Cholinesterase deficiency } \\
\hline No & $43(95.6 \%)$ & $17(37.8 \%)$ & \multirow[t]{2}{*}{$<0.001$} \\
\hline Yes & $2(4.4 \%)$ & $28(62.2 \%)$ & \\
\hline \multicolumn{4}{|l|}{ Anemia } \\
\hline No & $42(93.3 \%)$ & $22(48.9 \%)$ & \multirow[t]{2}{*}{$<0.001$} \\
\hline Yes & $3(6.7 \%)$ & $23(51.1 \%)$ & \\
\hline \multicolumn{4}{|l|}{ Thrombocytopenia } \\
\hline No & $45(100.0 \%)$ & $36(80.0 \%)$ & \multirow[t]{2}{*}{0.002} \\
\hline Yes & $0(0.0 \%)$ & $9(20.0 \%)$ & \\
\hline
\end{tabular}

statistical significance. White blood cells (WBCs) were also more decreased in the rural residence group than the other one. The mean acetylcholinesterase level is $77.42 \pm 15.66 \mathrm{IU}$ in urban children and 38.02 $\pm 30.20 \mathrm{IU}$ in rural children (Table 4 and Fig. 1).

The correlations between acetylcholinesterase level and the other measured parameters were studied and it showed a strong positive correlation was found with red blood cells (RBCs) and hematocrit (HCT). A moderate positive correlation with found with hemoglobin (HB), mean corpuscular volume (MCV), mean corpuscular hemoglobin $(\mathrm{MCH})$ and mean corpuscular hemoglobin concentration (MCHC). A weak positive correlation was found with platelets (Table 5 and Fig. 2).

Eating unwashed vegetables and rural residence were significant independent risk factors for the development of cholinesterase deficiency as an indicator for chronic organophosphorus poisoning as a result of long-term exposure to pesticides (Table 6).

\section{Discussion}

Organophosphorus poisoning is a widespread problem facing millions of people around the world yearly according to the WHO [7] as the use of organophosphorus compounds is essential for agricultural purposes and exposure is unavoidable. Besides, these insecticides can cause household toxicity especially in children due to excessive unsafe use or not keeping them away from the children's reach.
In a study conducted in Washington State, Lu et al. [11] analyzed urine samples collected from 62 agricultural and 14 Urban children and found that organophosphorus metabolite levels were 3-6 times greater for agricultural children than for urban children. Moreover, Curwin et al. [12] reported that the estimated daily pesticide doses were higher for farm children than nonfarm children. As acetylcholinesterase is reported to be a specific biomarker of the organophosphorus pesticides exposure, this study was designed to explore and compare the average acetylcholinesterase level in children from both the agricultural and the non-agricultural pediatric groups as an indicator of the prolonged exposure to the organophosphorus pesticides considering that the exposure in the rural areas is higher and in more various ways of exposure, e.g., inhalation, skin contact, and ingestion. Medical history, clinical, and laboratory assessments of the children were performed, and the acetylcholinesterase level, the indicator of the exposure, was correlated to the other investigated hematological parameters.

In the current study, the rural residents showed a significant difference in weight, more visits to the fields, more prevalent unhealthy habits, e.g., eating vegetables without washing and keeping insecticides at home, previous organophosphorus toxicities, and family history of previous organophosphorus toxicities. Recurrent eye, respiratory, cardiac, central nervous system, muscle, gastrointestinal, and urinary were also more common in the rural group. 

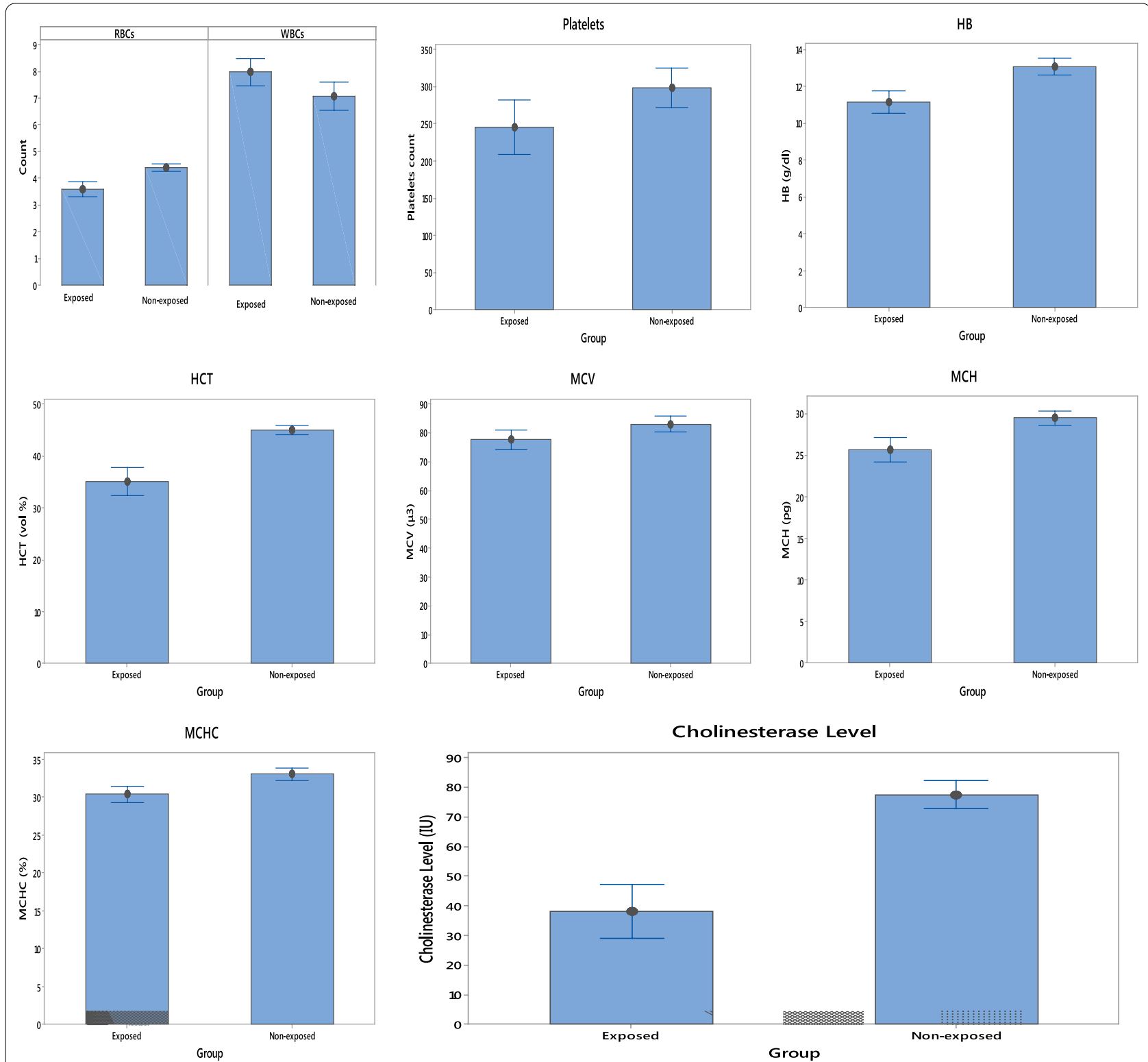

Fig. 1 Comparison between the exposed and non-exposed groups regarding the measured laboratory parameters. Significance was set at $p$ value less than 0.05 . Bars indicate the mean values with a boxplot of maximum and minimum values

In accordance with our clinical findings, Rastogi et al. [13] found that the organophosphorus pesticide-related eye symptoms observed in exposed rural children were blurred vision, burning sensation in the eye, lacrimation, and Miosis $4.9 \%$. The prevalence of organophosphorus pesticide-related respiratory symptoms observed in the exposed rural children was $5.7 \%$ bronchoconstriction and $3.11 \%$ chest pain. Amr et al. [14] found that topical eye changes were significant among the exposed group compared to the control subjects. Miosis, excessive salivation, convulsions, and other symptoms of acute cholinergic stimulation might be caused by organophosphorus pesticides inhibiting acetylcholinesterase. Pesticides may act on the respiratory system through one or more of the following mechanisms: (1) Non-specific irritation. (2) Allergic: pesticide or its solvent act as an antigen.

(3) Inhibition of acetylcholinesterase and build-up of Ach with bronchial cholinergic effects and spasms.

(4) Metabolic or trace element changes $(\mathrm{Cu}, \mathrm{Zn}, \mathrm{Ca}, \mathrm{Fe}$, etc., which are essential for ATP/ cAMP turn-over).

Regarding the cardiac symptoms, Rastogi et al. [13] found that the commonest organophosphorus 
Table 5 Correlations between cholinesterase and other study variables

\begin{tabular}{lcc}
\hline & \multicolumn{2}{c}{ Ch E Level } \\
\cline { 2 - 3 } & $\boldsymbol{R}$ & $\boldsymbol{p}$ \\
\hline Age & 0.064 & 0.551 \\
Weight & 0.019 & 0.858 \\
Height & 0.033 & 0.761 \\
BMl & $-0.077-$ & 0.473 \\
Hb & $0.666^{* *}$ & 0.000 \\
Platelets & $0.254^{*}$ & 0.016 \\
RBCs & $0.723^{* *}$ & 0.000 \\
WBCs & $-0.198^{-}$ & 0.062 \\
HCT & $0.791^{* *}$ & 0.000 \\
MCV & $0.489^{* *}$ & 0.000 \\
MCH & $0.646^{* *}$ & 0.000 \\
MCHC & $0.629^{* *}$ & 0.000 \\
Visits to field/week & 0.323 & 0.88 \\
\hline
\end{tabular}

* means significant difference $(p$-value $<0.05)$, ** means highly significant difference $(p$-value $<0.01)$

pesticide-related cardiac symptom was irregular heartbeats in $4 \%$ of the exposed children. Amr et al. [14] found that acetylcholinesterase activity below $60 \%$ showed significantly more cardiorespiratory problems, in which cardiac symptoms were significant among exposed than control. Moreover, Rasoul et al. [15] found that the participants in the agricultural group had more dizziness (24\%), difficulty in concentration (24\%), trouble in remembering (24\%), feelings of depression (26\%), irritability (22.\%), numbness (18\%), and fatigue (30.0\%), compared to the control participants $(8 \%, 8 \%, 8 \%, 6 \%, 10 \%$, $6 \%, 2 \%$, and $10 \%$, respectively) $(p<0.05)$. The conversion of thions $(\mathrm{P}=\mathrm{S})$ to oxons $(\mathrm{P}=\mathrm{O})$ in the body by the activity of liver microsomes, which are more toxic than thions, might be linked to the neurotoxic effects of organophosphorus pesticides. Damage to the afferent fibers of peripheral and central nerves, which is linked to the suppression of neuropathy target esterase, is another probable cause for delayed neurotoxicity. Organophosphate delayed neuropathy is the name given to this delayed condition, which is characterized by weakness, paralysis, and paresthesia in the extremities. The average cholinesterase level in this study was $77.4 \pm 15.7 \mathrm{IU}$ in the urban residence and $38 \pm 30.2$ IU in the rural residence. Leukocytosis was found in the rural residence group, and it was not correlated to the serum cholinesterase level. This coincides with earlier studies performed by Wafa et al. [16] and Hundekari et al. [17] who reported leukocytosis in the exposed group relative to the control. Leucocytosis can be an immune defense mechanism against OP chronic poisoning.
Wongta et al. [18] also found that vegetable growers had lower acetylcholinesterase activity compared with nonfarm workers at $p<0.05$. However, other studies doubted the role of acetylcholinesterase as a screening test $[9,10,19,20]$ but these studies did not explain the mechanism of toxicity for the symptoms associated with the prolonged exposure.

In the present study, red blood cell count was decreased with microcytic hypochromic anemia in the exposed group and these alterations were significantly correlated to the serum cholinesterase level. In accordance with these findings, Fareed et al. [21] and Wafaa et al. [16] reported the decreased red blood cells, hematocrit, and hemoglobin with chronic exposure to pesticides. Dalbó et al. [22] found that patients exposed to pesticides show results, with decreases in erythrocyte count and mean corpuscular volume. Erythrocyte count from 5.05 million $/ \mathrm{mm}^{3}$ to 4.98 million $/ \mathrm{mm}^{3}$ is within the normal range. The mean corpuscular volume from $85.62 \mathrm{~mm}^{3}$ to $82.64 \mathrm{~mm}^{3}$ can suggest a reduced synthesis of hemoglobin in the erythrocytes that resulted in smaller cells. However, the red cell distribution width (RDW) analyzed suggests changes in red blood cells, although not statistically significant. The RDW has been reported as an independent predictor of 30-day mortality in patients with organophosphorus poisoning.

The microcytic hypochromic anemia may result from the inhibition of red blood cells synthesis through the affection of the erythrocyte delta-aminolevulinic acid dehydratase (ALAD enzyme) associated with the organophosphorus exposure as reported by Hernández et al. [23].

In contrary to this finding, Sandra et al. [24], Parron et al. [25], and Fareed et al. [21] reported the erythrocytosis associated with chronic exposure to organophosphorus pesticides.

In the current study, thrombocytopenia was found in the exposure group and it was negatively correlated to the serum cholinesterase level. This comes in line with the reported finding of Sandra et al. [24], and this suggests that the hematotoxicity of the organophosphorus pesticides includes the reduction of synthesis of red blood cells and platelets.

The current findings showed that weight $\%$ was significantly decreased in the rural group that showed various recurrent symptoms of exposure as eye, chest, cardiac, central nervous system, muscle, gastrointestinal, and urinary complaints. Unhealthy habits as eating vegetables without cleaning were more common in the rural group. Family history of a previous organophosphorus poisoning was more increased in the rural group even with no past history of poisoning in the exposed child himself suggesting that the fact of Rohitrattanaet al. [26] that 

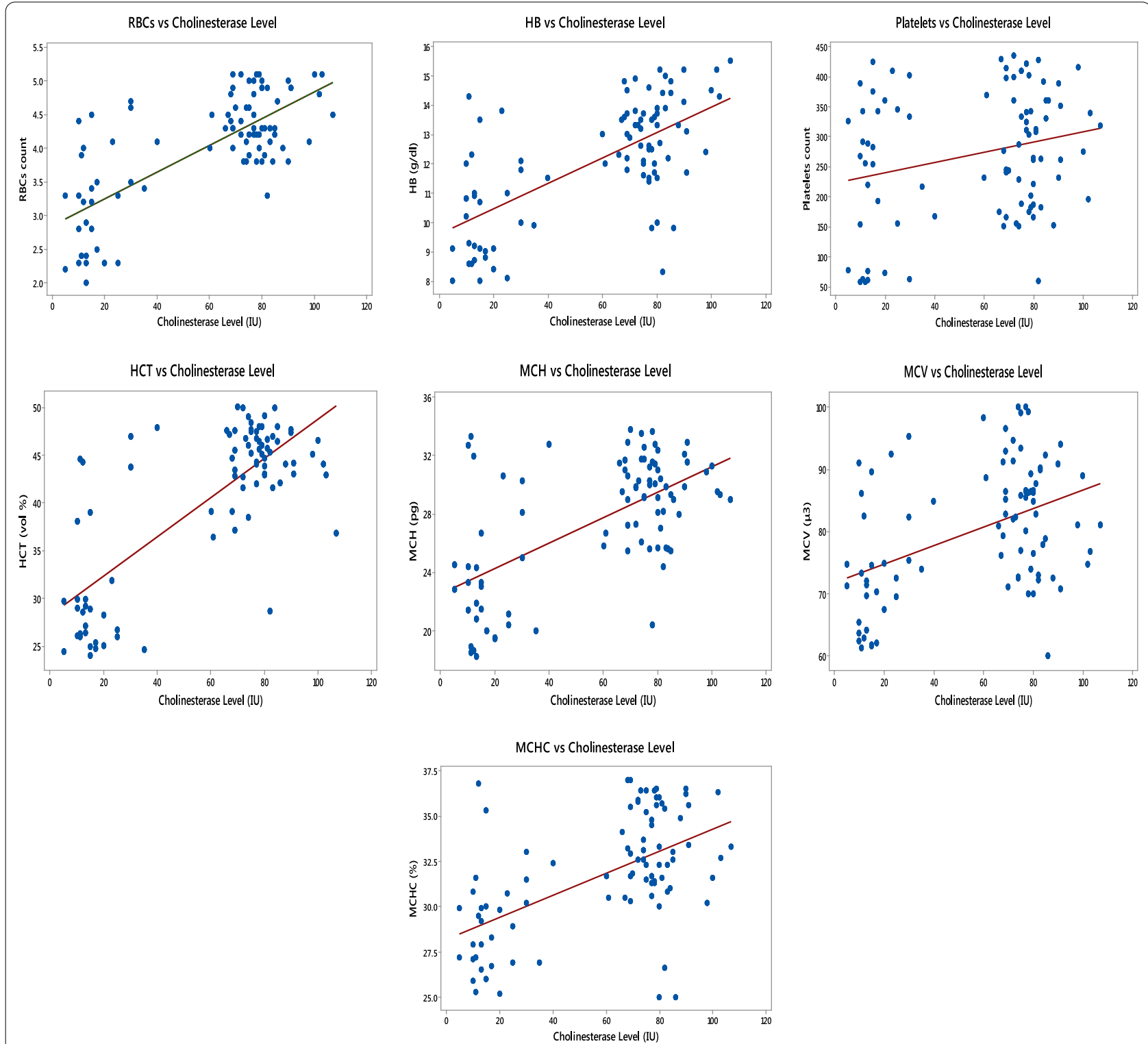

Fig. 2 Correlations of Cholinesterase level to the other measured laboratory parameters. Significance was set at $p$ value less than 0.05

Table 6 Multiple regression test to assess risk factors for ChE deficiency

\begin{tabular}{|c|c|c|c|c|c|}
\hline Independent variables & Coefficient & Std. error & $r_{\text {partial }}$ & $T$ & $P$ \\
\hline Eating unwashed vegetables & 0.7056 & 0.06717 & 0.7535 & 10.506 & $<0.0001$ \\
\hline Father work & 0.01294 & 0.05255 & 0.02685 & 0.246 & 0.8061 \\
\hline Insecticides at home & 0.06919 & 0.06190 & 0.1211 & 1.118 & 0.2669 \\
\hline Mother work & -0.01930 & 0.05088 & -0.04134 & -0.379 & 0.7055 \\
\hline Residence & 0.2125 & 0.05885 & 0.3666 & 3.611 & 0.0005 \\
\hline
\end{tabular}

acute toxicity can happen upon the unrevealed chronic poisoning. Also, they found significant associations between organophosphorus toxicity and being a member of a farming family $(p<0.001)$, parentally observed dirt on the body $(p=0.02)$, being with a parent on the farm $(p=0.02)$, playing on farms $(p=0.03)$, and frequency of OP application $(p=0.001)$. 


\subsection{Limitation}

This study had some limitations; first, the small sample size can affect the results. It would be more appropriate to conduct the study on different areas and a bigger group of children and we did not measure organophosphorus urinary metabolites to assess the exposure; further studies are needed to confirm the results and correlate acetylcholinesterase level with these metabolites.

\section{Conclusions}

Chronic organophosphorus poisoning can be the unrevealed cause of many recurrent unspecific symptoms. It causes children underweight and hematotoxicity in the form of microcytic hypochromic anemia and thrombocytopenia. The leucocytosis associated with chronic exposure to organophosphorus pesticides may indicate the stimulated immune response and should be further investigated. Rural exposure and unhealthy habits, e.g., eating vegetables without washing are possible risk factors.

\subsection{Recommendation}

This study sheds light on the importance of cholinesterase level as an indicator for chronic exposure to organophosphorus insecticides. Further wide epidemiological surveillance studies should be performed to define the normal level of the enzyme and evaluate its role as a screening test in children and adults. The mechanism of organophosphate chronic toxicity on Red blood cells synthesis and its immunotoxicity should be studied. Ministry of Health should raise with Media many health education programs for awareness of this problem especially in the rural community about the measures of self-protection against organophosphorus.

\section{Abbreviations \\ AChE: Acetylcholinesterase; Ach: Acetylcholine; RBCs: Red blood cells; OP: Organophosphate pesticides; MCV: Mean corpuscular volume.; MCH: Mean corpuscular hemoglobin.; MCHC: Mean corpuscular hemoglobin concentration.}

\section{Acknowledgements}

Not applicable.

\section{Authors' contributions}

Y.A.M. analyzed and interpreted the patient data. M.H.M. and K.M.A. supervised data collection and analysis. N.N.W. and R.E.I. helped in data analysis. F.A.S. collected the data. All authors have read and approved the manuscript.

\section{Funding}

Not applicable.

Availability of data and materials

Not applicable.

\section{Declarations}

Ethics approval and consent to participate

This study was approved by Ethics Committee of Beni-Suef University, Faculty of medicine and the ethics code was FWA00015547 FMBSUREC $\backslash 07062020$. Also, written informed consent was obtained from the parent of the participating children.

\section{Consent for publication}

Not applicable.

\section{Competing interests}

The authors declare that they have no conflict of interest.

\section{Author details}

${ }^{1}$ Department of Pediatrics, Faculty of Medicine, Beni-Suef University, Beni Suef, Egypt. ${ }^{2}$ Department of Clinical and Chemical Pathology, Faculty of Medicine, Beni-Suef University, Beni Suef, Egypt. ${ }^{3}$ Department of Forensic Medicine and Clinical Toxicology, Faculty of Medicine, Beni-Suef University, Beni Suef, Egypt.

Received: 30 June 2021 Accepted: 21 December 2021

Published online: 06 January 2022

References

1. Kaushal J, Khatri M, Arya SK (2020) A treatise on Organophosphate pesticide pollution: current strategies and advancements in their environmental degradation and elimination. Ecotoxicol Environ Saf 207:111483

2. Smith MN, Workman T, McDonald KM, Vredevoogd MA, Vigoren EM, Griffith WC, Faustman EM (2017) Seasonal and occupational trends of five organophosphate pesticides in house dust. J Expo Sci Environ Epidemiol 27(4):372-378

3. Krishnan JK, Figueiredo TH, Moffett JR, Arun P, Appu AP, Puthillathu N, Namboodiri AM (2017) Brief isoflurane administration as a post-exposure treatment for organophosphate poisoning. Neurotoxicology 63:84-89

4. Thompson CM, Gerdes JM, VanBrocklin HF (2020) Positron emission tomography studies of organophosphate chemical threats and oxime countermeasures. Neurobiol Dis 133:104455

5. Bocquené G, Bellanger C, Cadiou Y et al (1995) Joint action of combinations of pollutants on the acetylcholinesterase activity of several marine species. Ecotoxicology 4:266-279

6. Giyanwani PR, Zubair U, Salam O, Zubair Z (2017) Respiratory failure following organophosphate poisoning: a literature review. Cureus 9(9):e1651

7. Eddleston M (2019) Novel clinical toxicology and pharmacology of organophosphorus insecticide self-poisoning. Annu Rev Pharmacol Toxicol 59:341-360

8. Slavica V, Dubravko B, Milan J (2018) Acute organophosphate poisoning: 17 years of experience of the National Poison Control Center in Serbia. Toxicology 409:73-79

9. Lessenger JE, Reese BE (1999) Rational use of cholinesterase activity testing in pesticide poisoning. J Am Board Fam Pract 12(4):307-314

10. Strelitz J, Engel LS, Keifer MC (2014) Blood acetylcholinesterase and butyrylcholinesterase as biomarkers of cholinesterase depression among pesticide handlers. Occup Environ Med 71(12):842-847

11. Lu C, Fenske RA, Simcox NJ, Kalman D (2000) Pesticide exposure of children in an agricultural community: evidence of household proximity to farmland and take home exposure pathways. Environ Res 84(3):290-302

12. Curwin BD, Hein MJ, Sanderson WT, Striley C, Heederik D, Kromhout H, Alavanja MC (2007) Pesticide dose estimates for children of lowa farmers and non-farmers. Environ Res 105(3):307-315

13. Rastogi SK, Tripathi S, Ravishanker D (2010) A study of neurologic symptoms on exposure to organophosphate pesticides in the children of agricultural workers. Indian J Occup Environ Med 14(2):54

14. Amr MM (1999) Pesticide monitoring and its health problems in Egypt, a Third World country. Toxicol Lett 107(1-3):1-13 
15. Rasoul GMA, Abou Salem ME, Mechael AA, Hendy OM, Rohlman DS, Ismail AA (2008) Effects of occupational pesticide exposure on children applying pesticides. Neurotoxicology 29(5):833-838

16. Wafa T, Nadia K, Amel N, Ikbal C, InsafT, Asma K, Hedi MA, Mohamed H (2013) Oxidative stress, hematological and biochemical alterations in farmers exposed to pesticides. J Environ Sci Health B 48(12):1058-1069

17. Hundekari A, Suryakar AN, Rathi DB (2013) Acute organo-phosphorus pesticide poisoning in North Karnataka, India: oxidative damage, hemoglobin level and total leukocyte. Afr Health Sci 13(1):129-136

18. Wongta A, Sawarng N, Tongchai P, Sutan K, Kerdnoi T, Prapamontol T, Hongsibsong S (2018) The pesticide exposure of people living in agricultural community, Northern Thailand. J Toxicol 2018:1-7

19. Chen WL, Sheets JJ, Nolan RJ, Mattsson JL (1999) Human red blood cell acetylcholinesterase inhibition as the appropriate and conservative surrogate endpoint for establishing chlorpyrifos reference dose. Regul Toxicol Pharmacol 29(1):15-22

20. Marsillach J, Costa LG, Furlong CE (2013) Protein adducts as biomarkers of exposure to organophosphoruscompounds. Toxicology 307:46-54

21. Fareed M, Pathak MK, Bihari V, Kamal R, Srivastava AK, Kesavachandran CN (2013) Adverse respiratory health and hematological alterations among agricultural workers occupationally exposed to organophosphate pesticides: a cross-sectional study in North India. PLoS ONE 8(7):1-10

22. Dalbó J, Filgueiras LA, Mendes AN (2019) Effects of pesticides on rural workers: haematological parameters and symptomalogical reports. Cienc Saude Coletiva 24:2569-2582

23. Hernández AF, López O, Rodrigo L et al (2005) Changes in erythrocyte enzymes in humans long-term exposed to pesticides: influence of several markers of individual susceptibility. Toxicol Lett 159(1):13-21

24. Cortés-Iza SC, Rodríguez Al, Prieto-Suarez E (2005) Assessment of hematological parameters in workers exposed to organophosphorus pesticides, carbamates and pyrethroids in Cundinamarca. Salud Pública 19(4):468-474

25. Parrón T, Hernández AF, Pla A, Villanueva E (1996) Clinical and biochemical changes in greenhouse sprayers chronically. Hum Exp Toxicol 15(12):957-963

26. Rohitrattana J, Siriwong W, Tunsaringkarn T, Panuwet P, Ryan PB, Barr DB, Fiedler N (2014) Organophosphate pesticide exposure in school-aged children living in rice and aquacultural farming regions of Thailand. J Agromed 19(4):406-416

\section{Publisher's Note}

Springer Nature remains neutral with regard to jurisdictional claims in published maps and institutional affiliations.

\section{Submit your manuscript to a SpringerOpen ${ }^{\circ}$ journal and benefit from:}

- Convenient online submission

- Rigorous peer review

- Open access: articles freely available online

- High visibility within the field

- Retaining the copyright to your article 